QUIPURAMAYOC $\mid$ Revista de la Facultad de Ciencias Contables

Vol. 20 N. 37 pp. 54-60 (2012) UNMSM, Lima, Perú

ISSN: 1560-9103 (versión impresa) / ISSN: 1609-8196 (versión electrónica)

\title{
NUEVA CLASIFICACIÓN MUNDIAL DE TIPOS DE CONTABILIDAD [TODOS LOS QUE EXISTEN ACTUALMENTE EN EL MUNDO]
}

\author{
NEW TYPES INDEX OF ACCOUNTING \\ [ALL THAT CURRENTLY EXIST IN THE WORLD]
}

Román ARTURo Valdivia Ramos*

Docente Auxiliar de la Facultad de Ciencias Contables - UNMSM

[Recepción: Julio de 2012/ Conformidad: Agosto de 2012]

\section{RESUMEN}

En este trabajo de investigación, se señala una Nueva Clasificación Mundial de Tipos de Contabilidad que actualmente existen en el mundo. No conocemos una clasificación tan extensa y detallada como la que presentamos, producto de una larga labor de investigación académica.

Esta Clasificación, debe convertirse en la base y/o sustento de trabajos posteriores que se realicen o que lleven a cabo otros investigadores en el tema. Esta es una Clasificación única y singular, diferente a todo lo conocido hasta hoy. Este es el aporte que la Facultad de Ciencias Contables hace al mundo contable y al mundo empresarial.

Palabras claves: Contabilidad Científica, Tecnológica, Gubernamental, Internacional, Social.

\begin{abstract}
In this research, it signals a new World Ranking types of accounting that currently exist in the world. We do not know a rating as extensive and detailed as the one presented, the product of a long academic research.

This classification should be the foundation and / or support of further work to be carried or led by other researchers in the field. This is a rather unique classification, unlike anything known today. This is the contribution to the School of Accounting and makes the world accounting to the business world.
\end{abstract}

Keywords: Accounting Science, Technology, Government, International, Social.

\footnotetext{
* Doctorante en Ingeniería Industrial. Docente Investigador de la Facultad de Ciencias Contables. E-mail: arturo.valdivia. ramos@gmail.com
} 


\section{INTRODUCCIÓN}

El término Contabilidad proviene del latín "computare" que significa Contar. Incluye dos acepciones:

\section{a. Narrar}

Un sistema de Contabilidad debe ser narrativo en cuanto al orden cronológico de las tareas, trabajos y/o actividades.

b. Computar

En Contabilidad, todas las operaciones o transacciones deben registrarse en términos monetarios y expresarlas en cantidades.

La Contabilidad, sirve fundamentalmente para la toma de decisiones si no cumple con este objetivo, entonces pierde su esencia e integridad, es decir su razón de ser. Por otro lado, como la Contabilidad debe servir a inversionistas, clientes, empresarios, asesores, aseguradores, entre otros; es que existen diversos Tipos de Contabilidad

\section{OBJETIVO DE LA CONTABILIDAD}

Según la Lic. Adm. Janneth M. Thompson, el objetivo de la Contabilidad es proporcionar información de hechos económicos, financieros y sociales suscitados en una empresa $u$ organización; de forma continua, ordenada y sistemática, sobre la marcha y/o desenvolvimiento de la misma, con relación a sus metas y objetivos trazados.

Para este autor, el objetivo de la Contabilidad es contar, para luego medir (no al revés), es decir; primero se hacen los registros o anotaciones de las operaciones ya sea del día, semana, mes, semestre o anual y luego lo mide a través de la aplicación de índices, indicadores o ratios tanto financieros como no financieros para conocer la performance o desempeño (rendimiento) de una área o de toda la empresa.

\section{CONCEPTO DE LA CONTABILIDAD}

Para entrar a Clasificar los Tipos de Contabilidad, primero debemos dar algunos conceptos:

- El AICPA / Instituto Americano de Contadores Públicos Certificados, señala que la "Contabilidad es el arte de registrar, clasificar y resumir de manera significativa y en términos de dinero, transacciones y eventos que son en parte, por lo menos, de carácter financiero e interpretar los resultados de estos".

- El libro Contabilidad Básica y Documentos Mercantiles de Ayaviri García, Daniel, dice que la "Contabilidad es una ciencia y/o técnica que enseña a clasificar y registrar todas las transacciones financieras de un negocio o empresa para proporcionar informes que sirvan de base para la toma de decisiones sobre la actividad".

- McGraw-Hill, en su colección la Biblioteca de Contabilidad de Sydney, Davidson \& Roman, L. Weil, al respecto señalan que la "Contabilidad es un sistema de información, cuya finalidad es "ofrecer a los interesados información económica sobre una entidad”.

- En cambio, para Terán Gandarillas Gonzalo, la "Contabilidad es un instrumento de comunicación de hechos económicos, financieros y sociales suscitados en una empresa, sujeto a medición, registro e interpretación para la toma de decisiones empresariales". Con estos cuatro conceptos, podemos señalar entonces que la Contabilidad es un arte, una ciencia, un sistema de información y un instrumento de comunicación. Y es verdad.

\section{TIPOS DE CONTABILIDAD}

Diversos autores han hecho y han llevado a cabo diversas Clasificaciones sobre los Tipos de Contabilidad que existen en el mundo occidental. Los hay diversos y variados, algunos 
los han clasificado por su tamaño o magnitud (micro contabilidad y macro contabilidad), y otros por su aplicación. Otros investigadores, simplemente los han clasificado en Contabilidad Pública y Contabilidad Privada esto, de acuerdo al origen de los recursos y también los han clasificado de acuerdo a la actividad de la empresa, es decir en Contabilidad Industrial, Contabilidad Comercial, Contabilidad de empresas extractivas y en Contabilidad de servicios. Así de simple.

Otros especialistas en el tema, los han clasificado según la rigidez o adaptabilidad al cambio en Contabilidad de empresas lucrativas $y$ en Contabilidad de empresas sin fines de lucro, incluso los hay, quienes lo han clasificado en Contabilidad Manual y en Contabilidad Mecanizada y otros que los han clasificado en Contabilidad de Grandes Empresas, Contabilidad de Medianas Empresas y Contabilidad de Pequeñas y Micro-empresas, es decir, toman en cuenta la información que proviene del tamaño de la empresa. Los más precisos lo clasifican en Contabilidad Financiera, Contabilidad Administrativa, Contabilidad Fiscal y en Contabilidad de Costos.

Como se puede apreciar, existe una variedad y compleja Clasificación de Tipos de Contabilidad... pero, de todas las mencionadas, ninguna Clasificación siquiera sobrepasa a un docena (12).

Por primera vez, ahora tenemos una Clasificación de Tipos de Contabilidad que hemos denominado Mundial, por su extenso número de tipos y por utilizar una clasificación singular como es la Contabilidad Científica, Tecnológica, de Sectores Económicos, Gubernamental, Internacional, de Especialidades, Privada, de Servicios, Especial y Social, repetimos (es una clasificación) única y sin par.
Estamos seguros que esta Clasificación que proponemos, servirá de base y sustento a otros investigadores y/o estudiosos, que irán incrementando la lista que desde luego no tiene fin o límite.

\section{Los tipos de Contabilidad son:}

\section{CONTABILIDAD CIENTÍFICA}

Esta Contabilidad tiene como fundamento la lógica y las matemáticas. Su espectro es grande y extenso, debido a su enorme potencial, que está en el futuro. La Contabilidad, tenderá a ser más científica, es decir a ser más exacta y precisa y valorará aquello que aún la Contabilidad tradicional o moderna no puede registrar contablemente.

Estos Tipos de Contabilidad ya existen en la actualidad, pero son pocos aplicados por las empresas, porque rompen el paradigma contable.

1. Contabilidad Científica

2. Contabilidad Analítica

3. Contabilidad Matricial

4. Contabilidad de la Eficiencia-Eficacia

5. Contabilidad de la Innovación

6. Contabilidad de la Calidad

7. Contabilidad de la Productividad

8. Contabilidad del Valor Agregado

9. Contabilidad del Throughput

10. Contabilidad de la Competitividad

\section{CONTABILIDAD TECNOLÓGICA}

Esta Contabilidad es tecnológica porque aplica tecnologías debidamente probadas, y se basa en el modelo sistémico, holístico e helicoidal. Asimismo, los Tipos de Contabilidad Tecnológicos como el Benchmarking nos sirve para comparar los resultados obtenidos con el mejor de la competencia 
y la Contabilidad Virtual o la Contabilidad On-line, que utilizan tecnología innovadora, donde la rapidez, es su mayor fortaleza.

11. Contabilidad Técnica o Tecnológica

12. Contabilidad Virtual

13. Contabilidad On-line

14. Contabilidad Sistémica

15. Contabilidad Holística

16. Contabilidad Helicoidal

17. Contabilidad Outsourcing

18. Contabilidad Benchmarking o Contabilidad Comparada

19. Contabilidad Integral

20. Contabilidad Corner o de Esqina

III. CONTABILIDAD DE EMPRESAS O DE SECTORES ECONÓMICOS

Esta Contabilidad está referida a los tipos de empresas existentes o sectores económicos. Son muchos y variados, por lo tanto, solo estamos señalando a lo que a nuestro juicio, son los más relevantes. Si bien es cierto que todas estas Contabilidades en esencia son iguales, cada uno de estos Tipos de Contabilidad, tiene sus propias características y/o peculiaridades.

21. Contabilidad Minera

22. Contabilidad Hotelera

23. Contabilidad Turística

24. Contabilidad Agrícola

25. Contabilidad Pesquera

26. Contabilidad Farmacéutica

27. Contabilidad Hospitalaria

28. Contabilidad Inmobiliaria

29. Contabilidad Comercial

30. Contabilidad Industrial
IV. CONTABILIDAD GUBERNAMENTAL

Esta Contabilidad es una sola, pero tiene sus matices. Es aquella Contabilidad que se aplica en las entidades e instituciones del Estado que también son variadas y diversas. Es por ello, que existe la Contabilidad Municipal y la Contabilidad Regional; pero también tenemos la Contabilidad Fiscal, Aduanera o Portuaria, entre otros, que se especializan por la actividad que llevan a cabo.

31. Contabilidad Gubernamental o Pública

32. Contabilidad Municipal

33. Contabilidad Regional

34. Contabilidad Fiscal

35. Contabilidad Aduanera

36. Contabilidad Aero-portuaria

37. Contabilidad Portuaria

38. Contabilidad Marítima

39. Contabilidad Presupuestal

40. Contabilidad Forense

\section{CONTABILIDAD INTERNACIONAL}

Esta Contabilidad, se refiere a todo aquello que está relacionado con el exterior o el extranjero. Muchas empresas, sobre todo las Transnacionales han salido de sus fronteras para posicionarse en otros países a través de Agencias, Sucursales, Franquicias, entre otros. La Contabilidad Internacional, se ocupa de todo ello.

41. Contabilidad de Retail

42. Contabilidad de Franquicia

43. Contabilidad de Joint- Venture

44. Contabilidad de Empresas Transnacionales

45. Contabilidad de Agencias en el exterior.

46. Contabilidad de Sucursales en el extranjero 
47. Contabilidad Corporativa

48. Contabilidad de Distribución Internacional

49. Contabilidad de Export ó Import

50. Contabilidad Internacional

VI. CONTABILIDAD DE ESPECIALIDADES

Esta Contabilidad a diferencia de la Contabilidad Especiales está diseñada para aquellas empresas e instituciones especializadas en un rubro o negocio como son los bancos, compañías de seguros, AFP, entre otros.

Incluimos la Contabilidad para Pyme's, pues creemos que por sus propias características merece ser considerada como un Tipo de la Contabilidad de Especialidades.

\section{Contabilidad Bancaria}

52. Contabilidad de Seguros

53. Contabilidad de AFP

54. Contabilidad de Supermercados y Centros Comerciales

55. Contabilidad adaptada a las NIC

56. Contabilidad adaptada a las NIIF

57. Contabilidad de Organizaciones No lucrativas

58. Contabilidad de Transporte Aéreo

59. Contabilidad de Transporte Terrestre

60. Contabilidad para Pyme's

\section{CONTABILIDAD PRIVADA}

Esta Contabilidad es genérica, es decir se aplica a cualquier tipo o modelo de empresa, desde luego debidamente constituida. Aquí predomina la Contabilidad General, la Contabilidad Administrativa (también conocida como Contabilidad Gerencial) y la Contabilidad de Costos, que vienen a ser los pilares de todo el fundamento contable.
61. Contabilidad Básica

62. Contabilidad Intermedia

63. Contabilidad Avanzada

64. Contabilidad de Costos

65. Contabilidad Doméstica

66. Contabilidad Gerencial o Contabilidad

Administrativa

67. Contabilidad Simplificada

68. Contabilidad Financiera o Patrimonial

69. Contabilidad de Gestión o Directiva

70. Contabilidad General

\section{CONTABILIDAD DE SERVICIOS}

Esta Contabilidad está diseñada para las empresas e instituciones de servicio. Es así, que tenemos la Contabilidad Educativa o de Educación, la Contabilidad Crediticia, la Contabilidad de Cooperativas, entre otros. Pero solamente le está referida a las empresas de servicio, sino también para aquellas actividades de servicio que hay en las mismas como es la Contabilidad de Marketing, la Contabilidad de Ventas al menudeo, etc.

71. Contabilidad Educativa o de Educación

72. Contabilidad de Marketing

73. Contabilidad de Ventas al menudeo

74. Contabilidad Crediticia

75. Contabilidad Fiduciaria

76. Contabilidad Informática o Mecanizada

77. Contabilidad de Impuestos (No Contabilidad Fiscal)

78. Contabilidad de Stakeholders

79. Contabilidad de Cooperativas

80. Contabilidad de Organizaciones de Servicios

\section{CONTABILIDAD ESPECIALES}

Esta Contabilidad, como su nombre lo indica, está diseñada para aquellas empresas u organizaciones especiales, es por ello, que toma 
nombres suigéneris como Contabilidad de Posición, Contabilidad del Autónomo o Contabilidad de Flujo. Donde luego, que se pueden aplicar a cualquier empresa, pero lo que les caracteriza es su singularidad.

81. Contabilidad Aero-espacial

82. Contabilidad por Actividades

83. Contabilidad Centralizada

84. Contabilidad de Posición

85. Contabilidad del Autónomo

86. Contabilidad de la Matriz o de la compañía controladora

87. Contabilidad Sub-marina o Subacuática

88. Contabilidad de Flujo

89. Contabilidad de Intangibles

90. Contabilidad Especial

\section{CONTABILIDAD SOCIAL}

Esta Contabilidad está referida a todo lo social, humano y lo que le rodea. Sabemos que el capital más importante que tiene toda empresa o institución es el capital humano (no recurso humano), es decir, sus trabajadores los capitales dinero, infraestructura, mano de obra, han dado paso a nuevos capitales, como al que nos estamos refiriendo. La Contabilidad, por consiguiente, le debe dar al capital humano, el verdadero valor que siempre debió haber tenido. Pero, la Contabilidad Social no es única, va acompañada de los aspectos que rodean a la persona como es el cliente y el medio ambiente.

91. Contabilidad Humana

92. Contabilidad del Conocimiento

93. Contabilidad Laboral

94. Contabilidad Heurística

95. Contabilidad Teleológica o Proyectiva

96. Contabilidad del Régimen Especial

97. Contabilidad del Consumo

98. Contabilidad del Cliente o Relacional
99. Contabilidad Ambiental o Medio-Ambiente (Contabilidad verde)

100. Contabilidad Social

\section{CONCLUSIONES}

Hemos llegado a las siguientes Conclusiones:

1. La necesidad de presentar EE. FF. para terceros como son los inversionistas, proveedores, entidades públicas, etc.; hizo que la Contabilidad se especialice o divida en diversos tipos.

2. La Nueva Clasificación Mundial de Tipos de Contabilidad que proponemos, abarca 10 divisiones y 100 Tipos de Contabilidad, más que cualquier otra clasificación, realizada a la fecha.

3. Esta Nueva Clasificación debe servir de pauta, guía o derrotero a otros estudiosos e investigadores, para ir incrementando nuevos Tipos de Contabilidad que a medida que pase el tiempo, se irán agregando. Este proceso no termina nunca.

4. Los Tipos de Contabilidad se crean para ser más accesibles a los usuarios que cada vez son más especializados y exigentes y que deben estar acordes a los requerimientos $y$ avances científico-tecnológicos.

5. Estos no son los únicos Tipos de Contabilidad que existen en la actualidad, hay mucho más, así por ejemplo tenemos la Contabilidad Naval, la Contabilidad Ferretera, la Contabilidad Castrense, e incluso la Contabilidad Espacial, entre decenas de otros.

6. Los Intangibles o Inmateriales, tendrán otra base Contable pues con la actual es di- 
fícil de contabilizarlos. Desde luego, no nos estamos refiriendo a la Marca Patente, Royalty, Software, etc., sino al cliente, los stakeholders, al Know-How, el clima laboral, incluso al oxígeno que respiramos.

7. Pero... la Contabilidad es una sola y se basa en Principios.

\section{REFERENCIAS BIBLIOGRÁFICAS}

1. Tipos de Contabilidad. Lic. Adm. Janeth M. Thompson
2. Instituto Americano de Contadores Públicos Certificados AICPA

3. Contabilidad Básica y Documentos Mercantiles. Edición 1ㅜㄹ Editorial N-DAG, Argentina, pág. 10. Ayaviri García, Daniel

4. Biblioteca McGraw-Hill de Contabilidad Tomo I, Edición $3^{\circ}$, Editorial McGraw- Hill, pág. 1-3 Sydney, Davidson \& Roman, L. Weil

5. Temas de Contabilidad Básica e Intermedia 4ta Edición, Editorial Educación y Cultura, pág. 4. Terán Gandarillas, Gonzalo 